\title{
A CASE OF INVASIVE ABDOMINAL WALL FIBROMATOSIS PRESENTING AS INTRA-ABDOMINAL MASS
}

\author{
Khagokpam Hirina Devi1 ${ }^{1}$ Laitonjam Chinglensana², Manoharmayum Birkumar Sharma ${ }^{3}$, Harish Naik4 ${ }^{4}$ Minjur Ilango Deepak ${ }^{5}$
}

${ }^{1}$ Resident, Department of Surgery, Regional Institute of Medical Sciences, Imphal, Manipur, India.

${ }^{2}$ Assistant Professor, Department of Surgery, Regional Institute of Medical Sciences, Imphal, Manipur, India.

3 Professor, Department of Surgery, Regional Institute of Medical Sciences, Imphal, Manipur, India.

${ }_{4}^{4}$ Resident, Department of Surgery, Regional Institute of Medical Sciences, Imphal, Manipur, India.

${ }^{5}$ Resident, Department of Surgery, Regional Institute of Medical Sciences, Imphal, Manipur, India.

HOW TO CITE THIS ARTICLE: Devi KH, Chinglensana L, Sharma MB, et al. A case of invasive abdominal wall fibromatosis presenting as intra- abdominal mass. J. Evolution Med. Dent. Sci. 2019;8(21):1759-1761, DOI: 10.14260/jemds/2019/386

\section{PRESENTATION OF CASE}

A 26-year-old lady presented with a palpable mass of one and half year's duration, on the left side of her abdomen. It was painless but mild dragging sense was present. She had no history of fever, vomiting or any other complaint. She noticed the mass for the first time during her second trimester of third pregnancy. She had no history of previous surgery. Her bladder and bowel habits were normal.

On general examination, patient was afebrile, vitals were stable. Mild pallor was present. Abdominal examination revealed a fairly globular non-tender mass measuring $20 \mathrm{cms}$ across, occupying left flank and umbilicus. It was soft to firm in consistency and immobile.

FNAC reported as benign spindle cell tumour. A contrastenhanced computed tomography (CT) scan revealed a large heterogeneously enhancing well defined soft tissue intraabdominal mass in left flank and left retroperitoneum with invasion of left flank muscles suggestive of benign soft tissue tumour with minimal ascites [Figure 1]. At exploratory laparotomy, a mass of around $30 \mathrm{~cm} \mathrm{x} 25 \mathrm{~cm}$ was present extending from anterolateral abdominal wall into the retroperitoneum with multiple feeding vessels present, without any solid organ adherence [Figure 2]. The mass was excised completely. Gross examination of the cut section reveals firm whorled mass located within surrounded by skeletal muscle [Figure 3]. Histopathological examination revealed an intrabdominal fibromatosis with densely collagenised stroma and dilated vessels with myxoid change [Figure 4]. Microscopic picture of the tissue showed fish in a stream pattern and stellate cells [Figure 5]. There were no intraoperative or postoperative complications. Patient was discharged on $8^{\text {th }}$ postoperative day. Follow up till 2 years bears no evidence of recurrence.

Fibromatosis is an uncommon neoplasm that occurs sporadically or as part of an inherited syndrome like familial adenomatous polyposis (FAP) and Gardner syndrome. Abdominal wall fibromatosis has a slight female predominance. It accounts for $0.03 \%$ of all neoplasms and $3 \%$ of all soft tissue tumours.

'Financial or Other Competing Interest': None.

Submission 09-04-2019, Peer Review 13-05-2019,

Acceptance 20-05-2019, Published 27-05-2019.

Corresponding Author:

Dr. Laitonjam Chinglensana,

Singjamei Thongam Leikai,

Opposite SROY Club, Lane 3,

Imphal-795001, Manipur, India.

E-mail: chinglensana@rediffmail.com

DOI: $10.14260 /$ jemds $/ 2019 / 386$
A 26-year-old lady presented with a painless abdominal mass on left side of one and half year's duration without other symptoms. Fine needle aspiration cytology (FNAC) showed benign spindle cell tumour. A computed tomography revealed a large heterogeneously enhancing well defined soft tissue intra-abdominal mass in left flank and left retroperitoneum with invasion of left flank muscles suggestive of benign soft tissue tumour with minimal ascites. At exploratory laparotomy, a mass of around $30 \mathrm{~cm} \mathrm{x} 25 \mathrm{~cm}$ was present extending from anterolateral abdominal wall into the retroperitoneum with multiple feeding vessels present, without any solid organ adherence. The mass was excised completely. Histopathological examination reported as an intrabdominal fibromatosis.

Abdominal fibromatosis (AD) is benign myofibroblastic neoplasm originating from muscle aponeurosis. These tumours represent 0.03 to $0.1 \%$ of all neoplasms, and $1-3 \%$ of those affecting soft tissues. ${ }^{1-6}$ Deep fibromatosis affects a wide age range, but is most common between 10 and 40 years of age. They can develop in any musculo-aponeurotic structure and they may be located at virtually any anatomical site. The principal sites of involvement for extra-abdominal fibromatosis are the shoulder, chest wall and back, thigh and head and neck region. Intra-abdominal fibromatosis arises in the mesentery or pelvis while abdominal tumours arise from musculo-aponeurotic structures of the abdominal wall, especially the rectus and internal oblique muscles and their fascial coverings. ${ }^{7,8} \mathrm{AD}$ is the most common cause of anterior abdominal wall mass in young women. It lacks metastatic potential but have tendency for local infiltration and compression of surrounding structures.

\section{DISCUSSION}

The term "fibromatosis" describes a group of conditions that consist of fibroblastic proliferation in a collagenous extracellular matrix. Fibromatosis can be either superficial (Fascial) or deep (Musculoaponeurotic). In 2002, the World Health Organization used the term 'desmoid-type fibromatosis' for deep fibromatosis ${ }^{9}$ which is usually called a desmoid tumour. It can be further classified on the basis of its anatomic location, such as abdominal wall, intra-abdominal, or extra-abdominal. About 2 to 4 new cases occur per one million persons per year.10 It is usually associated with female gender, FAP, oestrogen therapy or after surgical trauma. ${ }^{11}$ It is usually prevalent in women who experienced pregnancy. However, intra-abdominal fibromatosis shows no gender difference or age predilection. It is locally aggressive and invasive and has a high propensity for recurrence. Although ultrasonography is often the first-line imaging investigation for a palpable mass, ultrasound features are non-specific. 


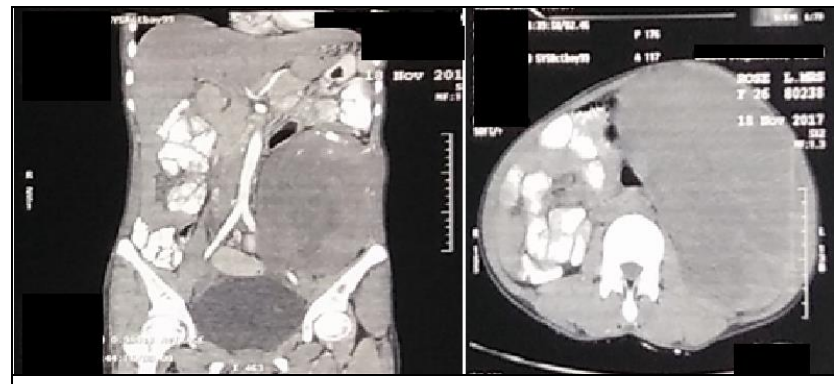

Figure 1. CECT Showing Tumour Extending from Left Flank with Intra-Abdominal Extension Umbilicus

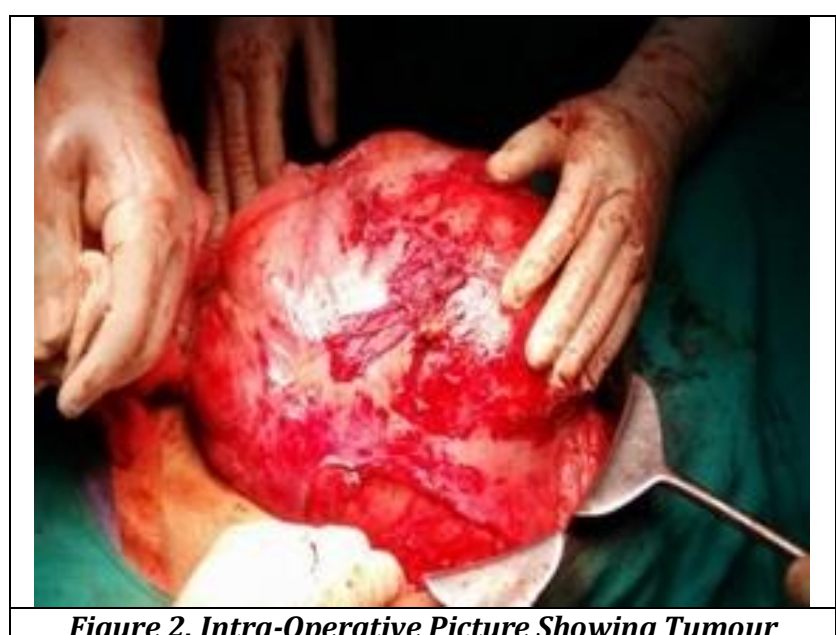

Figure 2. Intra-Operative Picture Showing Tumour

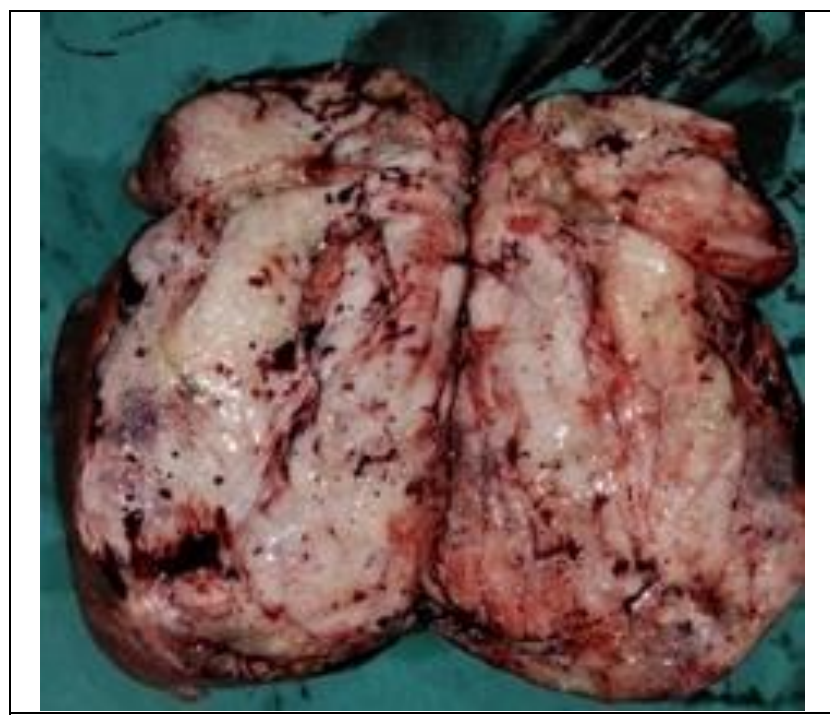

Figure 3. Cut Section of Tumour Showing Firm Whorled Muscle Mass

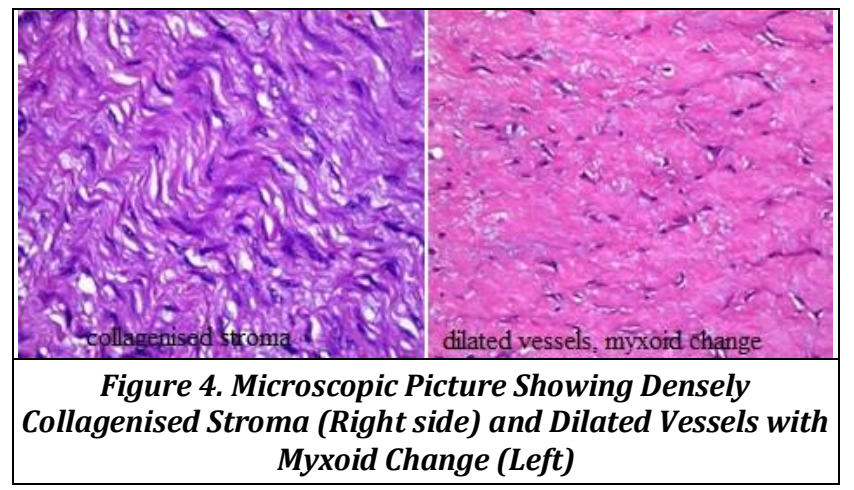

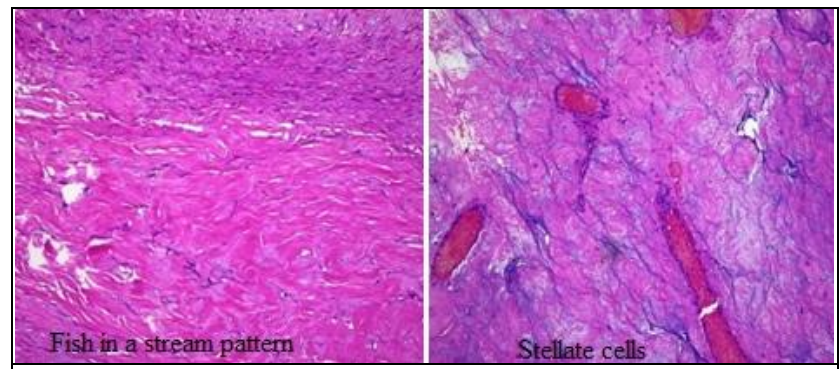

Figure 5. Microscopic Picture Showing Fish in a Stream Pattern (Right) and Stellate Cells (Left).

At CT, it appears as a soft-tissue mass, either sharply marginated, as most commonly seen in abdominal-wall tumours, or with ill-defined infiltrative margins, as seen in extra-abdominal or mesenteric tumours. Deep fibromatosis shows variable attenuation, similar to or slightly higher than that demonstrated by skeletal muscle, with hyper/hypoattenuation, probably reflecting collagen and myxoid elements, respectively. Enhancement is variable, with the majority of the masses demonstrating mild-to-moderate enhancement.

Magnetic resonance imaging (MRI) is the mainstay of imaging in deep fibromatosis and can be used for primary diagnosis, local surgical staging and follow-up. Its superior soft-tissue contrast allows accurate evaluation of tumour borders and their relationship to adjacent structures including muscles, nerves, blood vessels and bones.

A multidisciplinary approach can help patients to receive optimal management. Stable, asymptomatic patients can be observed. Margin-negative resection has historically been the gold standard for treatment of abdominal wall and intraabdominal desmoid tumours. However, recurrence is common. The recurrence rate is $15-30 \%$ for intra-abdominal fibromatosis. Therefore, completeness of resection is an important prognostic factor.

In a study looking at 50 patients with abdominal wall desmoid fibromatosis treated with surgery, $92 \%$ of patients did not experience recurrence after a median follow up of 6 years. In another study by Stojadinovic et al, recurrence rate of $68 \%$ was reported in patients resected with positive margin within 5 years. ${ }^{12}$ Radiotherapy, chemotherapy and endocrine therapy can be tried in inoperable tumours, local recurrences or incompletely excised lesions.

When effectiveness, side effects, and efficacy are weighed, either combination or single agent hormonal and nonsteroidal anti-inflammatory drugs (NSAID) agents are frequently used as a first-line systemic therapy for unresectable, recurrent or progressing desmoid tumours.13,14 Typically either tamoxifen (60-120 mg/day) or raloxifene (120-240 mg/day) is used as an anti-oestrogen agent. The NSAID most commonly used is sulindac $(150-800 \mathrm{mg} /$ day $)$. Some centres have adopted a first line "watch and wait" policy with interval imaging at every $3-6$ months with MRI.

\section{CONCLUSION}

Abdominal wall fibromatosis presenting as an intraabdominal mass with retroperitoneal extension was successfully managed with complete excision of the tumour with clear margins. Deep fibromatosis should be considered 
in differential diagnosis as it is the most common cause of an anterior abdominal wall mass in females of childbearing age. Core biopsy is mandatory for proof of diagnosis. Surgical excision remains the standard treatment of symptomatic abdominal wall and intra-abdominal desmoid tumours.

\section{REFERENCES}

[1] Shields CJ, Winter DC, Kirwan WO, et al. Desmoid tumours. Eur J Surg Oncol 2001;27(8):701-6.

[2] Sutton RJ, Thomas JM. Desmoid tumours of the anterior abdominal wall. Eur J Surg Oncol 1999;25(4):398-400.

[3] Lewis JJ, Boland PJ, Leung DH, et al. The enigma of desmoid tumours. Ann Surg 1999;229(6):866-72.

[4] Kulaylat MN, Karakousis CP, Keaney CM, et al. Desmoid tumour: a pleomorphic lesion. Eur J Surg Oncol 1999;25(5):487-97.

[5] Dalén BP, Bergh PM, Gunterberg BU. Desmoid tumours: a clinical review of 30 patients with more than 20 years' follow-up. Acta Orthop Scand 2003;74(4):455-9.

[6] Mendenhall WM, Zlotecki RA, Morris CG, et al. Aggressive fibromatosis. Am J Clin Oncol 2005;28(2):211-5.

[7] Fletcher CDM, Bridge JA, Hogendoorn PCW, et al. WHO classification of tumours of soft tissue and bone. Pathology and Genetics of Tumours of Soft Tissue and Bone. 4th edn. Lyon: IARC Press 2013.
[8] Kasper B, Baumgarten C, Bonvalot S, et al. Management of sporadic desmoid-type fibromatosis: a European consensus approach based on patients' and professionals' expertise - a sarcoma patients EuroNet and European Organisation for Research and Treatment of Cancer/Soft Tissue and Bone Sarcoma Group initiative. Eur J Cancer 2015;51(2):127-36.

[9] George V, Tammisetti VS, Surabhi VR, et al. Chronic fibrosing conditions in abdominal imaging. Radiographics 2013;33(4):1053-80.

[10] Reitamo JJ, Häyry P, Nykyri E, et al. The Desmoid Tumour. I. Incidence, sex-, age-and anatomical distribution in the Finnish population. American Journal of Clinical Pathology 1982;77(6):665-73.

[11] Soravia C, Berk T, McLeod RS, et al. Desmoid disease in patients with familial adenomatous polyposis. Diseases of the Colon \& Rectum 2000;43(3):363-9.

[12] De Cian F, Delay E, Rudigoz RC, et al. Desmoid tumour arising in a cesarean section scar during pregnancy: monitoring and management. Gynecologic Oncology 1999;75(1):145-8.

[13] Hansmann A, Adolph C, Vogel T, et al. High-dose tamoxifen and sulindac as first-line treatment for desmoid tumours. Cancer 2004;100(3):612-20.

[14] Tanaka K, Yoshikawa R, Yanagi H, et al. Regression of sporadic intra-abdominal desmoid tumour following administration of non-steroidal anti-inflammatory drug. World J Surg Oncol 2008;6:17. 